\title{
STRONGLY SEMI-APOSYNDETIC CONTINUA ARE HEREDITARILY LOCALLY CONNECTED
}

\author{
ELDON J. VOUGHT
}

\begin{abstract}
A stronger form of semi-aposyndesis is defined and used to characterize those compact, metric continua which are hereditarily locally connected.
\end{abstract}

In [1], Bennett raised the question as to whether strongly aposyndetic continua are necessarily hereditarily locally connected. The purpose of this paper is to give an affirmative answer to the question and to prove the somewhat stronger theorem of the title. A continuum $M$ is strongly aposyndetic if $M$ is decomposable and whenever $H$ and $K$ are proper subcontinua such that $M=H \cup K$, then $H$ and $K$ are aposyndetic. The continuum $M$ is strongly semi-aposyndetic if $M$ is aposyndetic and whenever $H$ and $K$ are proper subcontinua such that $M=H \cup K$, then $H$ and $K$ are semi-aposyndetic. Since a strongly aposyndetic continuum $M$ is easily seen to be aposyndetic it is not necessary to insist that $M$ be aposyndetic in the definition. However, in the semi-aposyndetic case, requiring $M$ to be decomposable does not insure that $M$ is aposyndetic which it must be in order for the theorems of this paper to be valid. The method of proof will be to first show that an aposyndetic continuum in which every subcontinuum with nonvoid interior is semi-aposyndetic is necessarily hereditarily locally connected. Secondly, it will be proved that a strongly semi-aposyndetic continuum has the property that every subcontinuum with nonvoid interior is semi-aposyndetic. These two results together will complete the proof.

Throughout, a continuum is to be a compact, metric, connected topological space. A continuum $M$ is aposyndetic at $p$ where $p$ is a point of $M$ if for every point $q$ in $M-p$ there exists an open set $U$ in $M$ and a subcontinuum $H$ in $M$ such that $p \in U \subset H \subset M-q$. If $M$ is aposyndetic at $p$ for each $p$ in $M$ then we say that $M$ is aposyndetic. A continuum $M$ is semi-aposyndetic at $\{p, q\}$ where $p$ and $q$ are distinct points of $M$ if there is

Received by the editors July 15, 1971.

AMS 1970 subject classifications. Primary 54F20, 54F50.

Key words and phrases. Aposyndetic continuum, semi-aposyndetic continuum, strongly aposyndetic, strongly semi-aposyndetic, hereditarily aposyndetic, hereditarily locally connected.

(c) American Mathematical Society 19:2 
an open set $U$ in $M$ and a subcontinuum $H$ in $M$ such that either $p \in U \subset$ $H \subset M-q$ or $q \in U \subset H \subset M-p$. If $M$ is semi-aposyndetic at $\{p, q\}$ for each pair of distinct points $p$ and $q$ in $M$ then we say that $M$ is semi-aposyndetic. Finally, a property of a continuum is hereditary if the continuum and each of its subcontinua has the property. For terms used but not defined see [2].

The method of proof of Theorem 1 is based on Theorem 5 of [4] combined with an alternating arc technique due to L. E. Rogers [3].

THEOREM 1. A compact, metric continuum $M$ is hereditarily locally connected if and only if $M$ is aposyndetic and every subcontinuum of $M$ with nonvoid interior is semi-aposyndetic.

ProOF. Hereditarily locally connected continua are characterized as those continua which contain no nondegenerate continuum of convergence [2, p. 196]. So let us assume that $M$ is aposyndetic and every subcontinuum of $M$ with nonvoid interior is semi-aposyndetic but $M$ contains a nondegenerate continuum of convergence $K$, i.e., $K=\lim K_{i}$, where each $K_{i}$ is a continuum, $K_{i} \cap K_{j}=\varnothing$ for $i \neq j$ and $K \cap K_{i}=\varnothing$ for all $i$. Let $x$ and $y$ be two points of $K$. Since $M$ is aposyndetic there is an open set $U$ in $M$ and a continuum $H$ in $M$ such that $x \in U \subset H \subset M-y$. No generality is lost by assuming that $H$ intersects all of the $K_{i}$ 's. Let $y_{1}, y_{2}, \cdots$ be a sequence such that $y_{i} \in K_{i}-H$ and $\lim y_{i}=y$ (in order to get this sequence it may be necessary to take a subsequence of the $K_{i}$ 's). Denote by $K_{i}^{\prime}$ a subcontinuum of $K_{i}$ that is irreducible from $y_{i}$ to $H$. The continuum $H \cup K \cup\left(\cup K_{i}^{\prime}\right)$ has a nonvoid interior and is therefore semi-aposyndetic. By $\left[3\right.$, p. 5] each $K_{i}^{\prime}$ is an arc and therefore $K_{i}^{\prime} \cap H$ is a single point, call it $k_{i}$. Let $k=\lim k_{i}$ where $k$ is a point of $K \cap H$ (again it may be necessary to take a subsequence of the $k_{i}$ 's). Because $M$ is aposyndetic there is a continuum $L$ in $M$ and open set $V$ in $M$ such that $y \in V \subset L \subset M-k$. Again, no generality is lost by assuming that $L$ intersects each $K_{i}^{\prime}$. In addition it can be assumed that $k_{i} \notin L$ for each $i$. Let $Q_{i}$ be the subarc of $K_{i}^{\prime}$ that is irreducible from $k_{i}$ to $L$ and let $q_{i}=Q_{i} \cap L$. Let $q=\lim q_{i}$ (again taking a subsequence if necessary). Then $q$ is a point of $L \cap K$. Denote by $s_{1}, s_{2}, \cdots$ and $t_{1}, t_{2}, \cdots$ two sequences such that (1) $s_{i} \cup t_{i} \subset Q_{i}$, (2) $k_{i}<s_{i}<t_{i}<q_{i}$ in the order of $Q_{i}$ from $k_{i}$ to $q_{i}$, (3) $\lim s_{i}=k, \lim t_{i}=q$. If $i$ is an odd positive integer let $Q_{i}^{\prime}$ be the subarc of $Q_{i}$ from $k_{i}$ to $t_{i}$ and if $i$ is an even positive integer let $Q_{i}^{\prime}$ be the subarc of $Q_{i}$ from $s_{i}$ to $q_{i}$. The continuum $H \cup L \cup K \cup\left(\cup Q_{i}^{\prime}\right)$ is a continuum that is not semi-aposyndetic at $\{k, q\}$. However, it has a nonvoid interior in $M$ and this contradiction establishes the theorem.

THEOREM 2. The compact, metric continuum $M$ is strongly semiaposyndetic if and only if $M$ is aposyndetic and every subcontinuum of $M$ with nonvoid interior is semi-aposyndetic. 
Proof. Assume that $M$ is strongly semi-aposyndetic and let $H$ be a subcontinuum of $M$ with nonvoid interior. In order to show that $H$ is semi-aposyndetic it can be assumed that $H$ is a proper subcontinuum of $M$ since $M$ itself is aposyndetic and hence semi-aposyndetic. Let $p$ be a point in $U$ where $U$ is an open set of $M$ contained in $H$. Since $M$ is aposyndetic, components of $M-p$ must be open sets and in addition there can be at most a finite number that intersect $M-U$. Otherwise, $M$ would contain an infinite sequence without a limit point. Consequently all but a finite number of these components lie in $H$. Denote by $C_{1}, C_{2}, \cdots, C_{n}$ the components of $M-p$ that intersect $M-H$ and let $Q_{i}=H \cup C_{1} \cup C_{2} \cup$ $\cdots \cup C_{i-1} \cup C_{i+1} \cup \cdots \cup C_{n}$ (if $C_{1}$ is the only component of $M-p$ intersecting $M-H$ then $Q_{1}=H$ ). Because $p$ is a nonseparating point of the subcontinuum $C_{i} \cup p$ and $M$ is aposyndetic at each point of $C_{i}$ with respect to $p$, we can assume that $C_{i}-U$ is connected. Now $M=\left(C_{i}-U\right) \cup Q_{i}$ where $C_{i}-U$ and $Q_{i}$ are proper subcontinua of $M$. Therefore, $C_{i}-U$ and $Q_{i}$ are semi-aposyndetic for each $i$ from 1 to $n$. Let $s$ and $t$ be any two points of $H=\cap Q_{i}$. Suppose that for some $i$ both $s$ and $t$ are in $H \cap C_{i}$. Since $Q_{i}$ is semi-aposyndetic at $\{s, t\}$ we can assume without loss of generality that there is a continuum $R$ and an open set $V$ in $Q_{i}$ such that $s \in V \subset R \subset$ $Q_{i}-t$. If $R$ lies in the continuum $H \cap\left(C_{i} \cup p\right)$ then $V$ is an open set in $H$ and $H$ is aposyndetic at $s$ with respect to $t$. If $R \notin H \cap\left(C_{i} \cup p\right)$ then $R-p=$ $A \cup B$, a separation, with $A \cup p$ being a continuum lying in $H \cap\left(C_{i} \cup p\right)$. Then $V \cap C_{i}$ is an open set in $H$ containing $s$ and lying in the continuum $A \cup p$. In this case also, $H$ is aposyndetic at $s$ with respect to $t$. By considering other locations of $s$ and $t$ in $H$, e.g., $s \in H \cap C_{i}, t=p$, or $s \in H \cap C_{i}$, $t \in H \cap C_{j}, i \neq j$, and using similar arguments to the one above it can be concluded that $H$ is a semi-aposyndetic continuum. This completes the proof of Theorem 2.

Combining Theorems 1 and 2 we have:

THEOREM 3. A compact, metric continuum $M$ is hereditarily locally connected if and only if $M$ is strongly semi-aposyndetic.

Let $M$ be an aposyndetic, compact, metric continuum and suppose that whenever $M=H \cup K$ where $H$ and $K$ are proper subcontinua of $M$, then either $H$ or $K$ is aposyndetic (or semi-aposyndetic). Does this imply that $M$ is hereditarily locally connected?

\section{REFERENCES}

1. D. E. Bennett, A sufficient condition for countable-set aposyndesis, Proc. Amer. Math. Soc. 32 (1972), 578-584.

2. K. Kuratowski, Topologie, Vol. II, 3ième éd., Monografie Math., Tom 21, PWN, Warsaw, 1961. MR 24 \#A2958. 
3. L. E. Rogers, Continua in which only semi-aposyndetic subcontinua separate, Pacific J. Math. (to appear).

4. E. J. Vought, A classification scheme and characterization of certain curves, Colloq. Math. 20 (1969), 91-98. MR 38 \#6550.

Department of Mathematics, Chico State College, Chico, California 95926 (Current address)

Department of Mathematics, University of Oklahoma, Norman, Oklahoma 73069 